\title{
Relação entre os Sinais de Fragilidade e a Capacidade do Idoso Viver Só
}

\author{
Yara Neves dos Santos $^{l}$; Aldrina da Silva Confessor Cândido ${ }^{2}$
}

\begin{abstract}
Resumo: A metodologia utilizada consistiu na Revisão Integrativa da Literatura. Organizou-se a revisão seguindo as etapas propostas pelas mesmas autoras, as quais foram: $1^{\text {a }}$ etapa: seleção da temática e das questões de pesquisa; $2^{a}$ etapa: estabelecimento dos critérios de inclusão e exclusão dos estudos; $3^{\mathrm{a}}$ etapa: definição das informações a serem obtidas e categorização dos estudos; $4^{\mathrm{a}}$ etapa: avaliação dos resultados; $5^{\mathrm{a}}$ etapa: interpretação dos resultados e $6^{a}$ etapa: descrição da síntese dos conhecimentos. O presente trabalho tem como objetivo geral de relacionar os sinais de fragilidade nos idosos e a capacidade de permanecer vivendo só. Como resultados apresentados identifica-se $\mathrm{O}$ envelhecimento pode ser temporariamente uma fase da vida que começa em algum período indeterminado, que segue a maturidade havendo o momento de fragilidade que se sente isolado não querendo preocupar ou interromper a vida social de algum familiar, outra coisa a frisar é Causas que levam o idoso a viver só Sendo identificados Dificuldades enfrentadas pelos idosos principalmente os processos fisiológicos e patológicos, desenvolvendo estratégias sociais e surgindo sinais de impactos de fragilidade. Acredita-se que os resultados desse estudo possam estar contribuindo para uma melhor garantia na atenção ao idoso no momento de fragilidade.
\end{abstract}

Palavras - chave: Idosos. Capacidade funcional. Fragilidade.

\section{Relationship between the Signs of Fragility and the Ability of the Elderly Living alone}

\begin{abstract}
The methodology used consisted of the Integrative Review of Literature. The review was organized following the steps proposed by the same authors, which were: 1st stage: selection of thematic and research questions; 2nd stage: establishment of inclusion criteria and exclusion of studies; Step 3: definition of the information to be obtained and categorization of the studies; Step 4: evaluation of results; 5th stage: interpretation of the results and 6th stage: description of the synthesis of knowledge. The present work has as general objective to relate the signs of fragility in the elderly and the ability to remain living alone. As results presented, it is identified. Aging can be temporarily a phase of life that begins at some indeterminate period, which follows maturity, when there is the moment of fragility that feels isolated not wanting to worry or interrupt the social life of a relative, something else Stress is Causes that lead the elderly to live only Being identified Difficulties faced by the elderly mainly the physiological and pathological processes, developing social strategies and emerging signs of fragility impacts. It is believed that the results of this study may be contributing to a better guarantee in the attention to the elderly in the moment of fragility.
\end{abstract}

Keywords: Elderly. Functional capacity. Fragility.

\footnotetext{
${ }^{1}$ Graduanda do Curso de Enfermagem da FAINOR, Contato: E-mail: nevys32htp@ hotmail.com

${ }^{2}$ Enfermeira - Docente do Curso de Enfermagem da FAINOR. Especialista em Formação Pedagógica para Profissionais de Saúde. Mestre em Gerontologia Social. Doutoranda em Humanidades e Arte com ênfase em Ciências da Educação. Contato: aldrina@fainor.com.br
} 


\section{Introdução}

O envelhecimento é um processo comum a todos os seres vivos, é uma experiência compartilhada por todo ser humano, mas nem sempre é compreendido. Desta maneira torna-se um fenômeno universal com perspectiva no Brasil, até o ano de 2025, sendo a sexta posição como o país mais envelhecido do mundo, alcançando cerca de 32 milhões de idosos, por isso é fundamental não somente entender o processo do envelhecimento, como também determinar as causas e as intervenções necessárias para uma melhor qualidade de vida (LUSTOSA et al., 2013).

Para Silva; Coronago (2016) o idoso tem seu momento de fragilidade e afeta principalmente a questão da saúde onde possui relação com a habilidade de fazer as coisas que deseja, trabalhar, poder ir e vir. Sendo assim, a qualidade de vida na velhice tem relação direta com a existência de condições que permitam aos idosos exercer comportamentos de característicos biológicos, sociais e psicológicos no sentido de adaptar a certas coisas. Assim, a decisão de viver sozinho, surge muitas vezes do próprio idoso sendo característicos por vários fatores relacionados a perdas humanas, insuficiência econômica, aposentadoria e abandono ou descaso e seus familiares.

O idoso em sua fase de vida passa pelo processo de ser incapaz para a sociedade onde esse termo se torna genérico que abrange deficiências, limitações de atividades e restrições à participação, incluindo a capacidade e o desempenho para executar uma tarefa. Portanto as metas da equipe de enfermagem englobam a promoção, manutenção e o auxílio para que os idosos identifiquem e utilizem seus potenciais para atingir a melhor independência e uma melhor maneira de viver.

Para Santos et al., (2015) o processo de envelhecer pressupõe alterações físicas, psicológicas e sociais no indivíduo, de forma natural e gradativa. São transformações gerais, que são visualizadas com precocidade ou na idade mais avançada, sendo em maior ou em menor grau, caracterizadas pela genética de cada indivíduo, e se dão principalmente de acordo com o modo de vida de cada um. Alguns fatores podem retardar ou vir a minimizar os efeitos da passagem do tempo, são eles: uma alimentação adequada, prática de exercícios físicos constantes, exposição moderada ao sol devido ao fator da vitamina D relacionado com sistema nervoso central, ocupação mental, controle do estresse, apoio psicológico e manter um estilo 
positiva perante a vida.

Vieira et al., (2013) afirma que o conceito fragilidade não tem algo definido em sua concretização, pois vários autores realizam de maneira distintas esse contexto, assim o idoso em seu momento fragilizado requer maior atenção voltado principalmente para sua saúde, onde possuem fatores de maior acontecimento de doenças crônicas, quedas, sintomas depressivos, limitações em atividades respondentes da vida diária e redução da autoeficácia, desta maneira essas característica possuem um perfil de idosos que vivem só, onde caracterizou por questão econômicas, fisiológicas e familiares. A enfermagem desempenha um papel de grande importância nesse contexto, buscando alternativas para mudar a mentalidade da sociedade, procurando fazer com que o idoso seja percebido e respeitado em suas carências, fazendo com que as pessoas consigam se colocar na condição do idoso, compreendendo-o integralmente.

Como problemática da pesquisa incluem: como é o perfil do idoso que vivem só? O presente trabalho tem como objetivo geral: relacionar os sinais de fragilidade nos idosos e a capacidade de permanecer vivendo só. Como objetivo específico, faz-se necessário: descrever o perfil dos idosos que vivem só; identificar as causas que levam os idosos a viverem só; descrever as principais dificuldades e estratégias dos idosos para viverem só; identificar sinais de fragilidade que influenciem na capacidade dos idosos permanecerem vivendo e apontar contribuições da enfermagem no cuidado a idosos que vivem só.

A relevância deste estudo desenvolve um papel importantíssimo no desenvolvimento de buscas para melhor atender o idoso e, sobretudo, o reconhecimento que a saúde é um direito social básico e de cidadania de todos, sendo importante frisar a produção cientifica contribuindo no foco da atenção à saúde do idoso de maneira geral, mas principalmente me seu momento de fragilidade onde os mesmos vivem só.

\section{Metodologia}

O presente estudo foi realizado a partir de dados registrados em fontes secundárias coletados por meio de levantamento bibliográfico, o que caracteriza a pesquisa bibliográfica que para (Lakatos e Marconi, 2010, p.25) 
A revisão bibliográfica é indispensável para a delimitação do problema em um projeto de pesquisa e para obter uma ideia precisa sobre o estado atual dos conhecimentos sobre um tema, sobre suas lacunas e sobre a contribuição da investigação para o para o desenvolvimento do conhecimento.

A metodologia utilizada consistiu na Revisão Integrativa da Literatura que de acordo com Mendes, Silveira e Galvão (2008, p.760) "possibilita a síntese do estado de conhecimento de um determinado assunto, além de apontar lacunas do conhecimento que precisam ser preenchidas com a realização de novos estudos".

Para tanto, organizou-se a revisão seguindo as etapas propostas pelas mesmas autoras, as quais foram: $1^{\text {a }}$ etapa: seleção da temática e das questões de pesquisa; $2^{\text {a }}$ etapa: estabelecimento dos critérios de inclusão e exclusão dos estudos; $3^{\mathrm{a}}$ etapa: definição das informações a serem obtidas e categorização dos estudos; $4^{\text {a }}$ etapa: avaliação dos resultados; $5^{\text {a }}$ etapa: interpretação dos resultados e $6^{\mathrm{a}}$ etapa: descrição da síntese dos conhecimentos.

A temática selecionada referiu-se aos sinais de fragilidade nos idosos e a capacidade de permanecerem vivendo só e, as questões de pesquisa elaboradas foram: qual o perfil dos idosos que vivem só? Que causas que levam os idosos a viverem só? Quais as principais dificuldades e estratégias dos idosos para viverem só? Quais os sinais de fragilidade que influenciem a capacidade dos idosos permanecerem vivendo só? Que contribuições a enfermagem pode dar no cuidado a idosos que vivem só?

O levantamento dos artigos para a revisão foi feita nas bases de dados Scielo e Google Acadêmico, no mês de abril de 2017, tendo como critérios de inclusão definidos para seleção: artigos publicados em português, que estivessem disponíveis na íntegra e com data de publicação nos últimos 5 anos. As palavras-chaves para a busca foram: "pessoas idosas que vivem só/sozinhos", "pessoa idosa frágil", "rede social de apoio ao idoso", "famílias unipessoais de idosos”. Foram identificados 495 materiais publicados entre 2013 e 2017 dos quais selecionou-se 14 artigos que atendiam aos objetivos da pesquisa.

Foi criado um roteiro para guiar o levantamento das informações e facilitar a categorização dos estudos. Partiu-se então para a leitura exaustiva dos artigos selecionados com o intuito de identificar e avaliar as informações, elaborando-se um corpo textual correspondente ao resultado da pesquisa. Esse resultado foi avaliado à luz da bibliografia, interpretado e descrito, compondo a síntese do conhecimento referente à temática proposta nesta pesquisa. 


\section{Resultados e Discussão}

\section{Sínteses das características dos estudos selecionados}

A presente tabela abaixo mostra os principais autores que discutem a respeito do objetivo da pesquisa sendo ressaltados artigos de 2013 a 2017, foram analisados 14 artigos onde mostramperfil sócio econômico dos idosos que vivem só, as causas que os levam a viver só, as dificuldades enfrentadas por eles, as estratégias utilizadas para viver só e a relação entre os sinais de fragilidade e a capacidade de viver só.

Tabela 1- Distribuição relativa quando a síntese do estudo bibliográfico.

\begin{tabular}{|c|c|c|c|}
\hline TÍTULO & AUTORES & PERIÓDICO & OBJETIVO \\
\hline $\begin{array}{l}\text { Idosos sozinhos: razões para } \\
\text { o envelhecer em domicílio } \\
\text { UNIPES. }\end{array}$ & $\begin{array}{l}\text { RAMOS, J. L. C.; } \\
\text { MEIRA, E. C.; } \\
\text { MENEZES, M. do R. }\end{array}$ & $\begin{array}{l}\text { Memorial idades, n. 19, } \\
\text { p.19-28, 2013. }\end{array}$ & $\begin{array}{l}\text { Pescrever os motivos que levam } \\
\text { o idoso a morar sozinho. }\end{array}$ \\
\hline Envelhecendo Para Viver Só & $\begin{array}{l}\text { ALENCAR, F. S; } \\
\text { SILVA, P. S. }\end{array}$ & $\begin{array}{l}\text { Memorial idades, n. } 19, \\
\text { p. } 117,2013 .\end{array}$ & $\begin{array}{c}\text { Analisar a realidade de idosos } \\
\text { que moram sozinhos }\end{array}$ \\
\hline $\begin{array}{l}\text { Prevalência e fatores } \\
\text { associados ao fenótipo da } \\
\text { fragilidade em idosos } \\
\text { brasileiros: uma revisão de } \\
\text { literatura }\end{array}$ & JUNIOR, E. P. P et al & $\begin{array}{c}\text { Revista Kairós } \\
\text { Gerontologia, 18(3), pp. } \\
\text { 353-366. 2013. }\end{array}$ & $\begin{array}{c}\text { Identificar os estudos que } \\
\text { abordam a prevalência e os } \\
\text { fatores associados ao fenótipo } \\
\text { de fragilidade em idosos } \\
\text { brasileiros. }\end{array}$ \\
\hline $\begin{array}{l}\text { Fatores associados a morar } \\
\text { sozinho e suas diferenças } \\
\text { regionais em idosos }\end{array}$ & $\begin{array}{c}\text { CAUDURO, A; } \\
\text { GONÇALVES, A. J; } \\
\text { CAUDURO, M. H. F }\end{array}$ & $\begin{array}{c}\text { Estud. interdiscipl. } \\
\text { envelhec., Porto Alegre, } \\
\text { v. 18, n. } 2 \text {, p. } 349-365, \\
2013\end{array}$ & $\begin{array}{c}\text { Verificar se características } \\
\text { sociodemográficas, estilo de } \\
\text { vida e estado da saúde estão } \\
\text { associados ao fato de o idoso } \\
\text { morar sozinho } \\
\end{array}$ \\
\hline $\begin{array}{l}\text { Comparação da percepção } \\
\text { subjetiva de qualidade de } \\
\text { vida e bem-estar de idosos } \\
\text { que vivem sozinhos, com a } \\
\text { família e institucionalizados }\end{array}$ & $\begin{array}{l}\text { DIAS, D. S. G; } \\
\text { CARVALHO, C. S; } \\
\text { ARAÚJO, C. V. }\end{array}$ & $\begin{array}{l}\text { Rev. Bras. Geriatr. } \\
\text { Gerontol. n.16n. 1, p. } \\
\text { 127-138, } 2013 .\end{array}$ & $\begin{array}{l}\text { Comparar a percepção subjetiva } \\
\text { de qualidade de vida e bem- } \\
\text { estar de idosos que vivem } \\
\text { sozinhos, com a família e } \\
\text { institucionalizados }\end{array}$ \\
\hline $\begin{array}{l}\text { Estratégias desenvolvidas } \\
\text { pelos idosos para viverem só }\end{array}$ & COSTA, M. F. & $\begin{array}{c}\text { Documento saúde, ano } \\
2013 . \\
\end{array}$ & \begin{tabular}{|l|} 
Analisar as estratégias dos \\
idosos que vivem sozinhos \\
\end{tabular} \\
\hline $\begin{array}{l}\text { A constituição de domicílios } \\
\text { unipessoais em condomínio } \\
\text { específico para idosos }\end{array}$ & $\begin{array}{l}\text { TESTON, E. F; } \\
\text { MARCON, S. S. }\end{array}$ & $\begin{array}{l}\text { Rev enferm UERJ, Rio } \\
\text { de Janeiro, n.22, v. 5, p. } \\
\quad 610-4,2014 .\end{array}$ & $\begin{array}{c}\text { Conhecer a percepção do idoso } \\
\text { que vive só com relação à } \\
\text { constituição dos domicílios } \\
\text { unipessoais }\end{array}$ \\
\hline $\begin{array}{l}\text { Síndrome de fragilidade no } \\
\text { idoso: uma revisão narrativa }\end{array}$ & $\begin{array}{l}\text { LANA, L. D; } \\
\text { SCHNEIDER, R. H }\end{array}$ & $\begin{array}{l}\text { Rev. Bras. Geriatr. } \\
\text { Gerontol, n. 17, n. 3, p. } \\
\text { 673-680, 2014. }\end{array}$ & $\begin{array}{l}\text { Analise do perfil dos idosos que } \\
\text { vivem só }\end{array}$ \\
\hline
\end{tabular}




\begin{tabular}{|c|c|c|c|}
\hline $\begin{array}{l}\text { Avaliação da fragilidade e } \\
\text { intervenções de enfermagem } \\
\text { indicadas para idosos }\end{array}$ & MACIEL, G. M. C & $\begin{array}{l}\text { v.13 (suppl I): p. 402-4, } \\
2014 .\end{array}$ & $\begin{array}{l}\text { Avaliar a fragilidade em idosos } \\
\text { atendidos na atenção primária à } \\
\text { saúde. }\end{array}$ \\
\hline $\begin{array}{l}\text { Prevalência e fatores } \\
\text { associados à síndrome da } \\
\text { fragilidade em idosos }\end{array}$ & $\begin{array}{l}\text { COLAÇO, L. V et } \\
\text { al., }\end{array}$ & $\begin{array}{c}\text { Anais CIEH }(2015)-\mathrm{V} . \\
\text { 2, N.1 }\end{array}$ & $\begin{array}{l}\text { Determinar a prevalência da } \\
\text { síndrome da fragilidade em } \\
\text { dosos, assim como identificar o } \\
\text { perfil sócio demográfico e de } \\
\text { morbidades preexistentes neste } \\
\text { grupo e apontar fatores } \\
\text { associados para o } \\
\text { desenvolvimento da fragilidade. }\end{array}$ \\
\hline $\begin{array}{l}\text { Perfil de fragilidade e } \\
\text { fatores associados em idosos } \\
\text { cadastrados em uma } \\
\text { Unidade de Saúde da } \\
\text { Família }\end{array}$ & SANTOS, H. S et al & $\begin{array}{c}\text { Ciência \& Saúde } \\
\text { Coletiva, n. 20, v. 6, p. } \\
\text { 1917-1924, 2015. }\end{array}$ & $\begin{array}{c}\text { Identificar o perfil de } \\
\text { fragilidade e os fatores } \\
\text { associados a idosos cadastrados } \\
\text { em uma Unidade de Saúde da } \\
\text { Família. }\end{array}$ \\
\hline $\begin{array}{c}\text { Etnografia de Idosos que } \\
\text { moram sozinhos: desafios e } \\
\text { possibilidades }\end{array}$ & $\begin{array}{c}\text { SILVA, L. O; } \\
\text { CORONAGO, V. M. } \\
\text { M. O }\end{array}$ & $\begin{array}{l}\text { Rev. Psic. V.10, N. 32, p. } \\
\text { 1179, 2016. }\end{array}$ & $\begin{array}{l}\text { Avaliar o perfil de idosos } \\
\text { que moram sozinhos. }\end{array}$ \\
\hline $\begin{array}{c}\text { Levantamento e } \\
\text { planejamento de uma } \\
\text { abordagem para o cuidado a } \\
\text { idosos que vivem sozinhos } \\
\text { na Estratégia de Saúde da } \\
\text { Família }\end{array}$ & Goulart, L. C. & $\begin{array}{l}\text { Monografia. Rio de } \\
\text { janeiro, 2016. } 15 \text { folhas. }\end{array}$ & $\begin{array}{l}\text { Planejar ações específicas e } \\
\text { orientação para esse grupo } \\
\text { através de visitas domiciliares e } \\
\text { consultas presenciais com } \\
\text { equipe multiprofissional. }\end{array}$ \\
\hline $\begin{array}{l}\text { Diagnostico Da Fragilidade } \\
\text { Em Idosos De Vitoria De } \\
\text { Santo Antão-Pe }\end{array}$ & QUEIROZ, A. S. & $\begin{array}{l}\text { Monografia. Vitória de } \\
\text { Santo Antão, 2017. } 25 \\
\text { folhas. }\end{array}$ & $\begin{array}{l}\text { Diagnosticar Fatores associados } \\
\text { à fragilidade em idosos }\end{array}$ \\
\hline
\end{tabular}

Fonte: Dados da pesquisa bibliográfica, 2017.

Embora não seja inteiramente satisfatória, a definição que melhor atende aos múltiplos aspectos que caracterizam o envelhecimento é aquele que o conceitua como um processo dinâmico e progressivo, no qual ocorrem alterações morfológicas, funcionais, bioquímicas e psicológicas. Tais mudanças determinam perda progressiva da capacidade de adaptação do indivíduo ao meio ambiente, ocasionando maior vulnerabilidade e maior incidência de processos patológicos que terminam por conduzir à morte (PINTO; COUTINHO, 2014).

Com o avançar do tempo, a sociedade vai passando por grandes transformações, algumas delas são: a tecnologia avançada, os meios de comunicação que nos bombardeiam com 
fatos e dados, a vida é cada vez mais agitada, o tempo cada vez menor e as condições econômicas são mais difíceis, principalmente à medida que as pessoas vivem mais.

Tudo isso exige uma capacidade de adaptação, que o idoso nem sempre possui, fazendo com que os mesmos enfrentem diversos problemas sociais e familiares, desta maneira alguns amigos e familiares acabam isolando (COUTO, 2013).

De acordo com o autor supracitado, o papel social dos idosos é um fator importante no significado do envelhecimento, pois o mesmo depende da forma de vida que as pessoas tenham levado, como das condições atuais que se encontram. Neste aspecto destacamos a aposentadoria, momento em que o indivíduo se distancia da vida produtiva. Na vida do homem, a aposentadoria muitas vezes acontece como uma descontinuidade. Há uma ruptura com o passado, o homem deve ajustar-se a uma nova condição que lhe traz certas vantagens, como o descanso, lazer, mas também graves desvantagens como desvalorização e desqualificação (BORGES et al., 2013).

\section{Perfis dos idosos que vivem só}

O traçado do perfil dos idoso que vivem só fica vidente da seguinte maneira de acordo com os quatorzeestudos analisados e discutidos: constam a idade dos idosos entre 60 a 91 anos, com ambos os sexos residem só, sendo a maioria do sexo feminino, 7 artigos relataram sobre renda e grau de instrução, 12 artigos identificam o devido sexo, sendo a maioria analfabeto, os que tem grau de escolaridade possuem até 1 grau completo, com renda mensal de até um salário mínimo. A média de tempo dos idosos que vivem só é 19/1 entre 14,7 anos.

\section{Causas que levam os idosos a viverem}

Conforme a figura 1, as causas que levam a pessoa idosa a viver só engloba 3 aspectos, pessoais, familiares e econômicas, quando se trata de pessoais possui uma ligação com autonomia, celibato, oportunidade para um bom remeço, no aspecto familiares já envolve abandono, descaso, separação e morte do companheiro, e por fim em meio econômico está 
relacionado com o poder aquisitivo adequado, todos esses artifícios são meios para idoso desenvolver uma fragilidade levando o desenvolvimento de viver só.
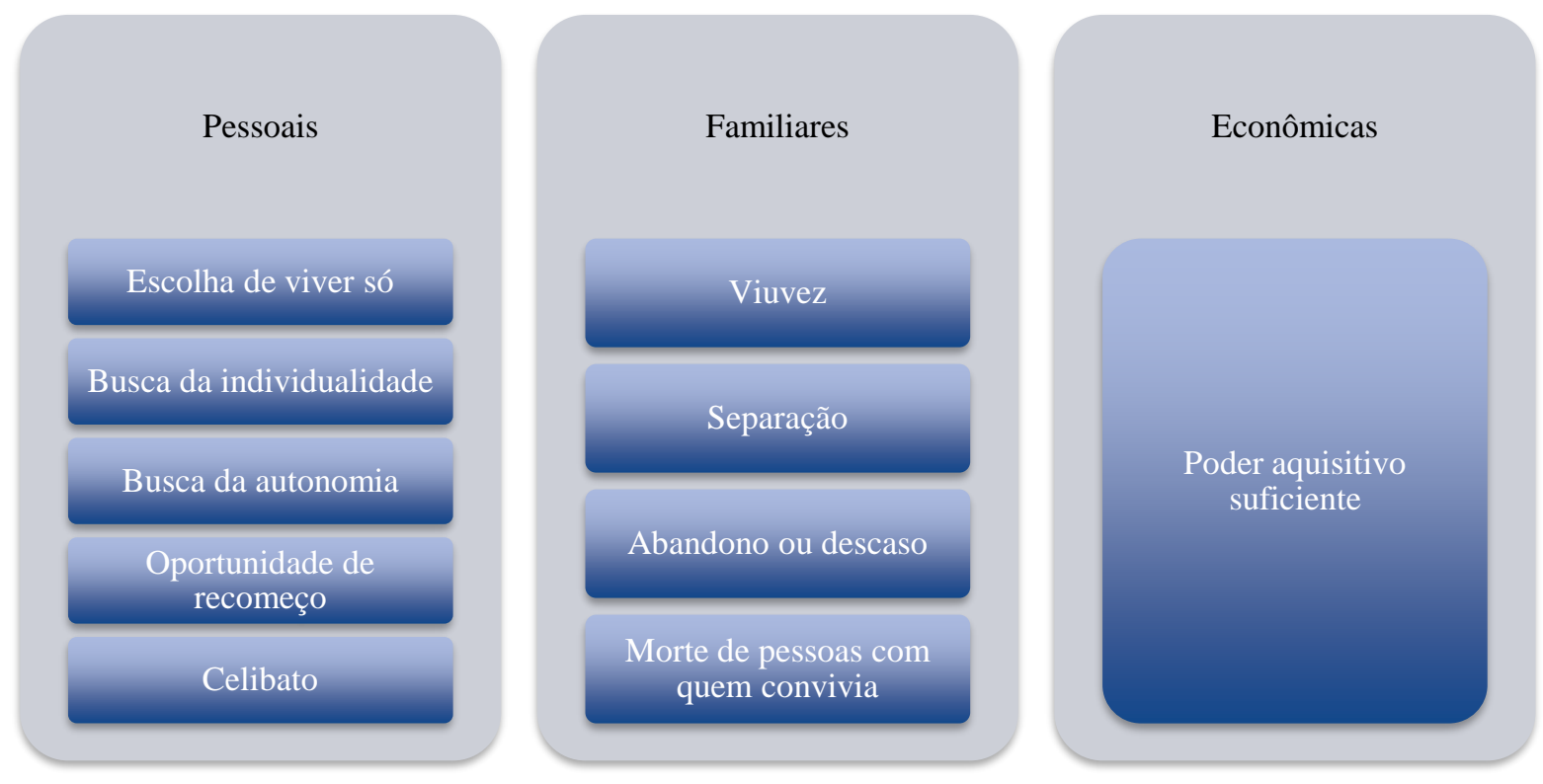

Figura 1: Causas que levam o idoso a viver só (Dados da pesquisa, 2017).

Para Alencar; Silva (2013) as motivações para esse crescente arranjo domiciliar de idosos que moram sem companhia são variados e sinalizados em diferentes estudos como consequência de rupturas como separação ou divórcio, viuvez, saída ou morte de filho, celibato; ou, simplesmente, a uma forma inovadora e bem sucedida de envelhecimento, evidenciando que nem toda pessoa idosa necessita, ou quer, viver com sua família

A decisão de morar sozinho, parte muitas vezes do próprio idoso motivado por fatores como: perdas humanas, insuficiência econômica, aposentadoria e abandono ou descaso e seus familiares (LEONARDO et al., 2014).

\section{Dificuldades enfrentadas pelos idosos que vivem}

A figura 2 representa a dificuldade dos idoso em viver só, onde surgem alterações patológicas e psicossociais, assim com a síndrome da fragilidade relacionado ao estado de 
moradia só, a pessoa idosa começam surgir diversos pensamentos e preocupações levando a desenvolvimento de fisiopatologias psicológicas e até cardíacas e renais. Vale ressaltar que o surgimento de problemas osteomusculares é uma das características em idoso
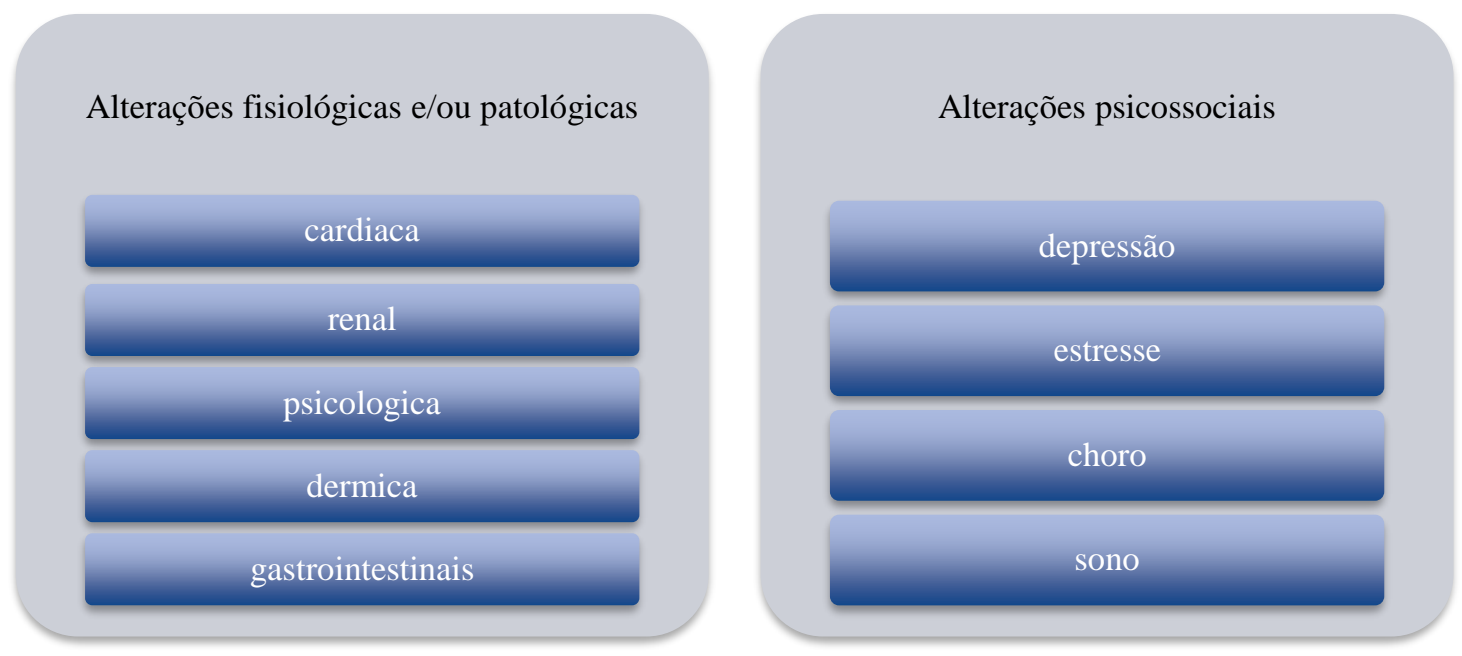

Figura 2: Dificuldades enfrentadas pelos idosos que vivem só

Nas últimas décadas tem ocorrido um importante processo populacional no Brasil e suas consequências já se fazem presentes no nosso cotidiano. No Brasil, segundo as projeções estatísticas da Organização Mundial de Saúde entre 1950 e 2025, a população de idosos crescerá 16 vezes contra o aumento de cinco vezes da população total (PINTO; COUTINHO, 2014).

Assim, no que diz respeito às mudanças e dificuldades dos idosos na conformação da estrutura etária populacional e às implicações destas mudanças nas políticas sociais e econômicas. Com o processo do envelhecimento populacional e o aumento da expectativa de vida, constataram-se transformações no perfil epidemiológico da população, com o predomínio das doenças crônicas não transmissíveis, além disso o idoso convive com o isolamento podendo desencadear diversas doenças relacionados as alterações fisiológicas do organismo (PEREIRA; SPYRIDES; ANDRADRE, 2016). 
Id on Line Revista Multidisciplinar e de Psicoloqia

Id on Line Multidisciplinary and Psycology Journal

\section{Estratégias criadas pelos idosos para permanecerem vivendo só}

A figura 3 ressalta o apoio familiar e de amigos, convívio em grupos, busca do bemestar psicológico e a questão religiosas é estratégias e características dos idosos que vivem só, pois esse meio leva ao convívio social sendo uma maneira de desvio para ocupação social.

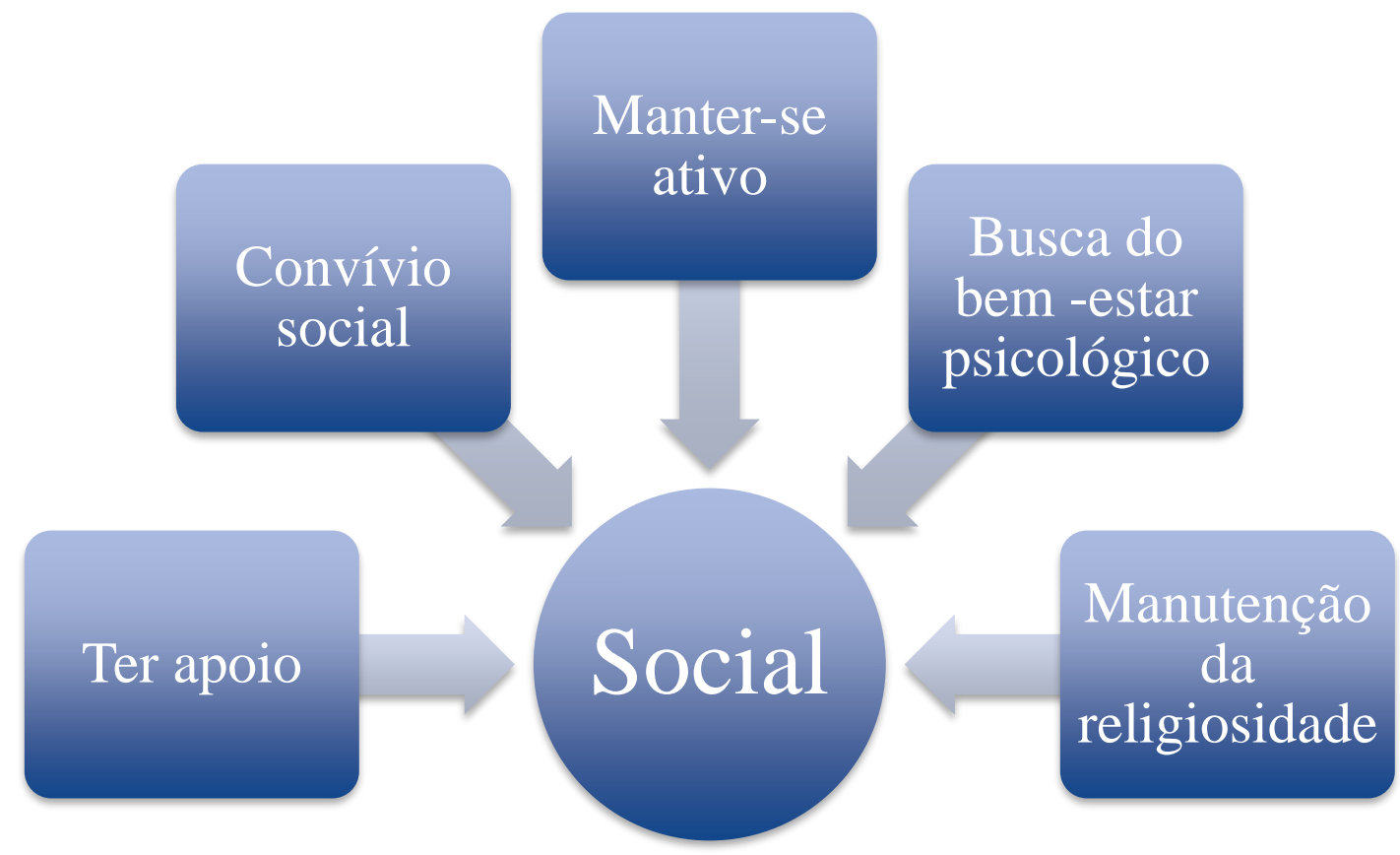

Figura 3: Estratégias dos idosos para viverem só

O organismo do ser humano vive um constante processo de mudanças, passando por diversas fases, cada fase do viver traz mudanças em que suas respostas são determinadas pelos acontecimentos no curso da vida, aprendendo a se adaptar às diversas e sucessivas transformações, uma dessas fases é o envelhecimento, ao contrário do que acontece com as outras fases, o envelhecimento não possui um marcador bi fisiológico do seu início.

A Síndrome da fragilidade está mais presente com a pessoa idosa de maneira avançada, sendo um estado de envelhecimento normal e o estado de incapacidade, analisando as condições 
distintas entre o processo de vivencia e o envelhecimento rápido relacionado com a fragilidade. Além disso, seus sinais e sintomas podem ser considerados amplos apresentando complicações na qualidade da saúde. Assim, pode-se perceber que o problema se torna de saúde pública, pois a expectativa de vida vem aumentando na pessoa idosa.

\title{
Sinais de Perda de peso não intencional fragilidade
}

\author{
Fadiga
}

\section{Diminuição da força de preensão manual}

\section{Atividade física reduzida}

\section{Diminuição da velocidade da marcha}

Figura 4: Sinais de fragilidade no envelhecimento

Os idosos frágeis possuem maior possibilidade de morte, incapacidade e hospitalização, em consequência de uma menor habilidade de resposta em situações de estresse e vulnerabilidade. Assim, surge a probabilidade de ocorrência de doenças crônicas, déficit cognitivo, problemas osteoarticulares e anorexia (COUTO, 2013).

\section{Relações entre os sinais de fragilidade e a capacidade de permanecer vivendo}

Assim, a figura 5 retrata os impactos e sinais de fragilidade do envelhecimento que envolve risco de queda, declínio funcional, incapacidade de maneira geral, perda da autonomia 
e dependência funcional, esses sinais surgem com o passar dos tempos indicando momento que o idoso necessita de uma maior atenção principalmente volta a respeito de sua saúde.

Impacto dos sinais de fragilidade no envelhecimento

\section{Risco maior para queda}

\section{Declínio funcional}

\section{Incapacidades}

\section{Perda da autonomia}

\section{Dependência funcional}

Figura 5: Sinais de impactos de fragilidade na fase do envelhecimento.

De acordo com Torres et al., (2006), idosos fragilizados são aqueles com empenho da capacidade funcional ou que exibem limitações advindas de doenças, lesões ou afecções, crônicas e agudas. Para os autores, a fragilidade é forte determinante de inaptidão e de dependência, mas mesmo assim com esses sinais os idosos quer permanecer independente achando que está tudo bem mas aí que se inicia os eventos sociais e psicológicos.

\section{Contribuições da enfermagem no cuidado ao idoso que vive só}

A enfermagem engloba assistência qualificada e sistematizada voltada para os cuidados individuais e coletivos de prevenção e manutenção da vida da população desenvolvendo processos educativos para a saúde inclusive dos idosos. E devido a isso o enfermeiro deve compreender sobre a atual situação em que se encontra oidoso, como ele está vivendo e qual a 
sua necessidade. Sabe-se que, por mais difícil que pareça é possível um trabalho realizado com qualidade e bons resultados na saúde.

A enfermagem deve reconhecer sua importância como educadora e agente de transformação social, esta deve ser uma constante em sua atuação profissional, porque a interação entre profissionais e usuários do sistema de saúde se faz principalmente através da enfermagem. Por fim o enfermeiro deve refletir de forma consciente sobre suas ações e atitudes no cuidado com o idoso, no sentido de possibilitar o desenvolvimento de práticas holísticas, reflexivas e capazes de subsidiar a assistência.

- Ainda acerca do benefício de uma melhor qualidade de vida ao idoso, pode-se possibilitar a eles vários tipos de entretenimento, um dia na semana de visitas teatrais, música, leitura, o conto de histórias, atividades ao ar livre, atividades culturais, organização de festas comemorativas, confecção de artesanato. Tudo isso se dá com o intuito de inseri-los em um âmbito igualitário tendo uma boa convivência social e humanizada,e também desempenhar um papel importante nos aspectos psicológicos. E sem deixar de frisar a importância do acompanhamento do enfermeiro juntamente com sua equipe da unidade de saúde a esses idosos que procuram a unidade e mesmo aqueles que por algum motivo não podem ir até ela sendo assim realizadas visitas domiciliares para acompanhamento dos mesmos.

\section{Considerações Finais}

Devido ao aumento cronológico do tempo de vida das pessoas, são observadas algumas mudanças, no cenário físico, biológico e/ou psicológico. O crescimento acelerado do número de idosos é obviamente a representação do aumento da expectativa de vida em todas as nações do mundo. Ao finalizar essa pesquisa pode-se notar que o envelhecimento para cada indivíduo se dá de formas distintas. Enquanto que para alguns pode gerar dificuldades, limitações e perdas, para outros o envelhecimento pode se dar de forma adequada, saudável e de maneira positiva.

Assim vários são os sinais de fragilidade nos idosos principalmente momentos de tristezas e de ter a capacidade de permanecer vivendo só. Mais de 50\% dos artigos pesquisados confirmam que o perfil dos idosos tem acima de 60 anos e vai até 91 anos e moram sozinho, 
vendo a família algumas vezes, se sentindo capaz e independe de realizar as atividades diárias e sociais, é importante a promoção, prevenção e manutenção da saúde do idoso focando no seu bem-estar, dos artigos analisados 12, identificam o devido sexo, sendo a maioria analfabeto, os que tem grau de escolaridade possuem até 1 grau completo, com renda mensal de até um salário mínimo. A média de tempo dos idosos que vivem só é 19/1 entre 14,7 anos.

Sendo assim o profissional de Enfermagem deve ter a capacidade de oferecer ao idoso uma assistência integral, facilitando sua adaptação as novas mudanças advindas com o envelhecimento e deve ter a capacidade de estabelecer com ele uma relação de carinho, respeito e tratá-lo com dignidade, atendendo às suas necessidades.

Para que isso seja alcançado é necessário que o profissional de enfermagem conheça e compreenda o processo do envelhecimento e que venha a estabelecer um plano de intervenção sistematizado, promovendo uma melhor qualidade de vida a esse idoso. Diante deste cenário, é igualmente necessário que os profissionais da área de saúde busquem melhorias relacionadas ao cuidar, proporcionando aos idosos atividades educativas, como: dias de lazer, cultura, religiosidade, oficinas e passeios.

\section{Referencias}

ALENCAR, F. S; SILVA, P. S. Envelhecendo Para Viver Só. Memorialidades, n. 19, p. 117, 2013.

COLAÇO, L. V et al., prevalência e fatores associados à síndrome da fragilidade em idosos. Anais CIEH (2015) - V. 2, N.1.

CALDAS, C. P et al., Rastreamento do risco de perda funcional: uma estratégia fundamental para a organização da Rede de Atenção ao Idoso. Ciência \& Saúde Coletiva, v. 18, n. 12. 2013.

CAUDURO, A; GONÇALVES, A. J; CAUDURO, M. H. F. Fatores associados a morar sozinho e suas diferenças regionais em idosos. Estud. interdiscipl. envelhec., Porto Alegre, v. 18 , n. 2 , p. $349-365,2013$.

COSTA, M. F. Estratégias desenvolvidas pelos idosos para viverem só. Documento saúde, ano 2013. 
DIAS, D. S. G; CARVALHO, C. S; ARAÚJO, C. V. Comparação da percepção subjetiva de qualidade de vida e bem-estar de idosos que vivem sozinhos, com a família e institucionalizados. Rev. Bras. Geriatr. Gerontol. n.16n . 1, p. 127-138, 2013.

GOULART, L. C. Levantamento e planejamento de uma abordagem para o cuidado a idosos que vivem sozinhos na Estratégia de Saúde da Família. Monografia. Rio de janeiro, 2016. 15 folhas.

JUNIOR, E. P. P et al., Prevalência e fatores associados ao fenótipo da fragilidade em idosos brasileiros: uma revisão de literatura. Revista Kairós Gerontologia, v. 18, n. 3, p. 353-366. 2013.

LIMA, P; FAJARDO, A. P. Aspectos Do Autocuidado Em Saúde Bucal De Idosos Hipertensos E Diabéticos Que Vivem Sozinhos. Rev.Aten. Saúde, São Caetano do Sul, v. 14, n. 50, p. 56-62, out./dez., 2016.

QUEIROZ, A. S. Diagnostico Da Fragilidade Em Idosos De Vitoria De Santo Antão-Pe. Monografia. Vitória de Santo Antão, 2017. 25 folhas.

LANA, L. D; SCHNEIDER, R. H. Síndrome de fragilidade no idoso: uma revisão narrativa. Rev. Bras. Geriatr. Gerontol, n. 17, n. 3, p. 673-680, 2014.

LAKATOS, E .M.; MARCONI, M. A. Técnicas de pesquisa. 6. ed. São Paulo: Atlas. 2006. $289 \mathrm{p}$.

MACIEL, G. M. C. Avaliação da fragilidade e intervenções de enfermagem indicadas para idosos. v.13 (suppl I): p. 402-4, 2014.

PEREIRA, I. F. S; SPYRIDES, M. H. C; ANDRADE, L. M. B. Estado nutricional de idosos no Brasil: uma abordagem multinível. Cad. Saúde Pública, Rio de Janeiro, v. 32 n. 5.2016.

RAMOS, J. L. C.; MEIRA, E. C.; MENEZES, M. do R. Idosos sozinhos: razões para o envelhecer em domicílio UNIPES. Memorialidades, n. 19, p.19-28, 2013.

TESTON, E. F; MARCON, S. S. A constituição de domicílios unipessoais em condomínio específico para idosos. Rev enferm UERJ, Rio de Janeiro, n.22, v. 5, p. 610-4, 2014.

SANTOS, A. M; LEITE, M. T. Modificações Ocorridas Na Vida De Familiares Que Cuidam De Idosos No Ambiente Doméstico. Revista Contexto \& Saúde, v. 6 n. 12. 2007.

SILVA, L. O; CORONAGO, V. M. M. O. Etnografia de Idosos que moram sozinhos: desafios e possibilidades. Rev. Psic. V.10, N. 32, p. 1179, 2016.

SANTOS, H. S et al., Perfil de fragilidade e fatores associados em idosos cadastrados em uma Unidade de Saúde da Família. Ciência \& Saúde Coletiva, n. 20, v. 6, p. 1917-1924, 2015. 
Id on Line Revista Multidisciplinar e de Psicoloqia

Id on Line Multidisciplinary and Psycology Journal

VIEIRA, R. A et al. Prevalência de fragilidade e fatores associados em idosos comunitários de Belo Horizonte, Minas Gerais, Brasil: dados do Estudo FIBRA. Cad Saude Publica 2013; 29(8):1631-1643.

\section{Como citar este artigo (Formato ABNT):}

SANTOS, Yara N.; CÂNDIDO, Aldrina da S. C. Relação entre os Sinais de Fragilidade e a Capacidade do Idoso Viver Só. Id on Line Revista Multidisciplinar e de Psicologia, Maio de 2017, vol.11, n.35, p. 463-478. ISSN: 1981-1179.

Recebido: 28.05.2017

Aceito: 29.05 .2017 